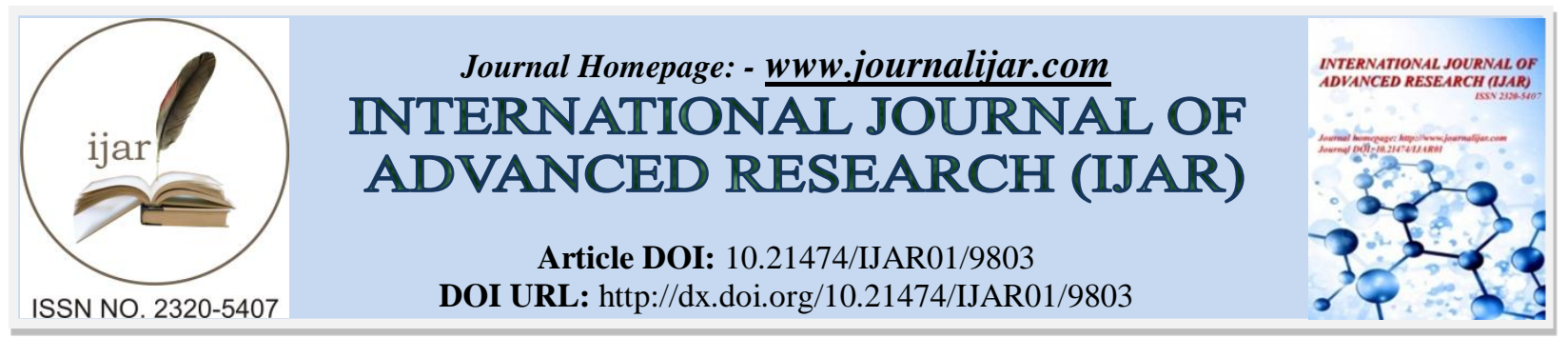

RESEARCH ARTICLE

\title{
ROBERT'S UTERUS MASQUERADING AS ADNEXAL TORSION IN A 13 YEAR OLD ADOLESCENTS: A CASE REPORT.
}

\author{
Jaouad Lafquir ${ }^{1}$, Fatima Elmangoub ${ }^{2}$, Rachid Ait bouhou ${ }^{2}$, Jaouad Kouach ${ }^{2}$ and Omar boukaidi \\ Laghzaoui ${ }^{1}$.
}

1. Department of Obstetrics and Gynecology, Military Training Hospital Moulay Ismail, Meknes,Morocco.

2. Department of Obstetrics and Gynecology, Military Training Hospital Mohammed V, University Hospital Ibn Sina, Rabat, Morocco.

\section{Manuscript Info}

.........................

Manuscript History

Received: 02 August 2019

Final Accepted: 04 September 2019

Published: October 2019

Key words:-

Müllerian anomaly; Robert's uterus;

Adnexal Torsion.

\section{Abstract}

Robert's uterus is a rare müllerian anomaly and unique malformation described as a septate uterus with non-communicating hemicavity.we here report the case of a 13-year old girls presented to the emergency departments with acute right iliac fossa pain associated nausea and vomiting . Fallopian tube torsion bringing about a hematosalpinx is suspected. Exploratory laparotomy showed findings a Robert's uterus and right hematosalpinx. Right uterine hemicavity and Fallopian tube was resected. The postoperative course was uneventful.

Copy Right, IJAR, 2019,. All rights reserved.

\section{Introduction:-}

In women, the uterus, the upper portion of the vagina and the tubes are formed from fusion of the paired mullerian ducts. Failure of development or fusion of the ducts gives rise to a variety of genital tract anomalies (1).Mullerian duct anomalies have an incidence of $0.1-3.5 \%$. Robert's uterus is a rare müllerian anomaly and unique malformation described as a septate uterus with non-communicating hemicavity; i.e. a blind uterine horn usually with unilateral hematometra, contralateral unicornuate shaped uterine cavity and normal external shape of the uterine fundus. After the onset of puberty,women often present symptoms, for example, dysmenorrhea and cryptomenorrhoea, dyspareunia, primary or secondary infertility, pregnancy loss and obstetric complications. The American Fertility Society (AFS) classification organises of mullerian anomalies (1988) according to major uterine anatomic defect and allows for standardized reporting methods. Septate uterus (AFS Class V) is the most common, resulting from incomplete resorption of the medial septum after complete fusion of the Mullerian ducts has occurred; variations exist like complete, partial and segmental.

\section{Case Presentation}

13 year old girl, without antecedent, she had her first rule for 3 months, girl presented to the emergency department with a severe right sided abdominal pain not relieved by analgesic with episodes of vomiting for one day but no constipation, diarrhea, urinary symptoms or fever. Besides being in pain,Her initial vital signs were correct. The abdomen was defender and tender to palpation in the right iliac fossa with voluntary guarding. A urinalysis, full hemogram and renal function tests that were done were essentially normal. Intravenous analgesics were given. The pain didn't subside. Ultrasonography (USG) revealed right adnexal cyst of $6.5 \mathrm{~cm} \times 4 \mathrm{~cm}$ size with absent vascularity (figure1). She was diagnosed as acute Fallopian tube torsion bringing about a hematosalpinx and was taken for surgical exploration. On laparotomy the following was noted; The right adnexa which was dark blue and 
twisted two and a half times in a clockwise direction bringing about a hematosalpinx and greatly dilated, (Figure 2), We also observed the basilar part of the uterus was wide and slightly hollow and a double corps uterus wa discoverd with one non-communicating right uterine horn. Hysterotomy incision was performed on the right uterine swelling surface and a visible brown viscous liquid flowing out of the right hemicavity. A uterine septum with the size of $1.5 \times 2 \mathrm{~cm}$ was found between the two uterine cavities which made the right horn non communicating which was consistent with the diagnosis of Robert's uterus. both ovary and left fallopian tube appeared normal. righ salpingectomy and a visible brown liquid flowed out with resection of the right hemicavity was performed(figure3). Histopathological examination was consistent with hematometrea. She recovered well after the operation without any complication. Repeat ultrasonography after 3 months was suggestive of a normal uterus with a normal endometrial lining.

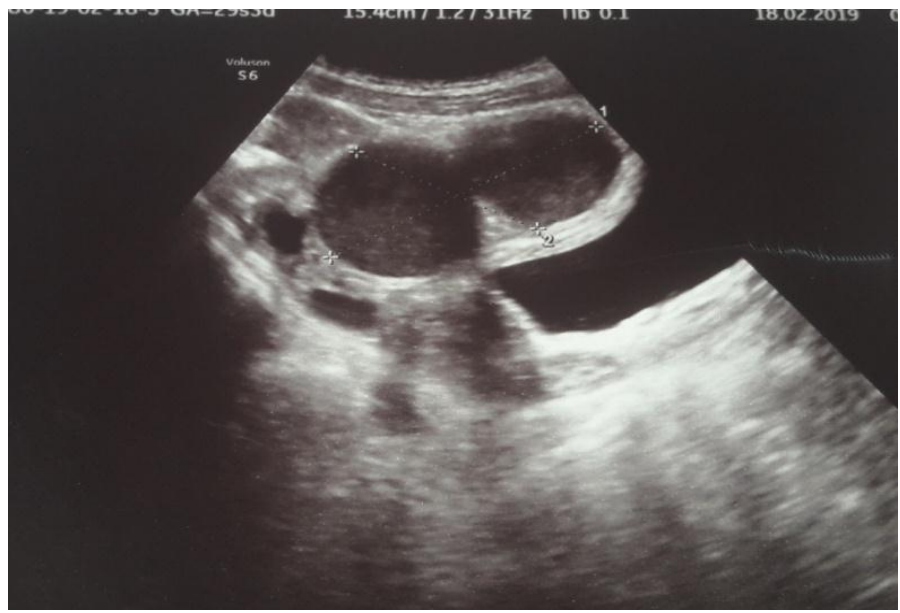

Figure 1:-Ultrasonography (USG) revealed right adnexal hematosalpinx.

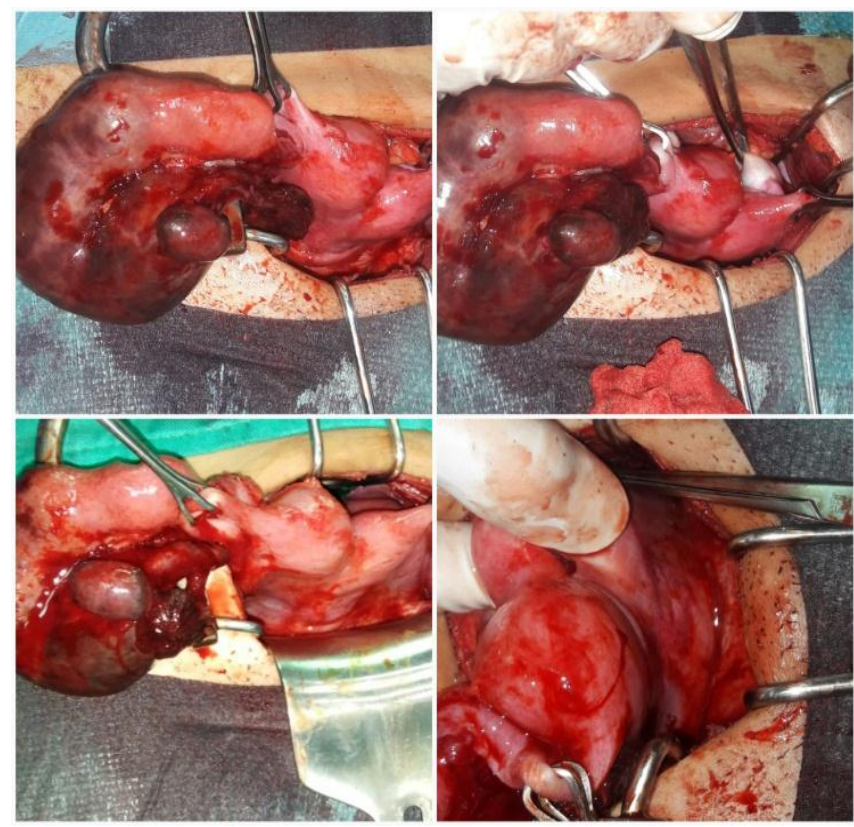

Figure 2:-Intraoperative findings. 


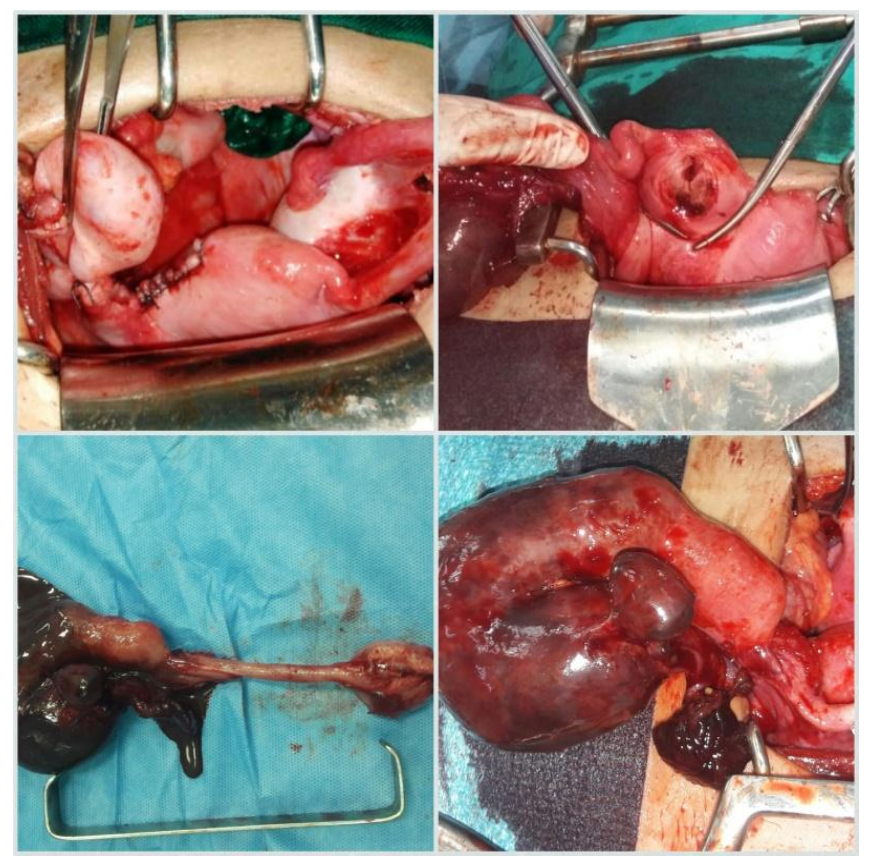

Figure 3:-Uterus after excision of right hemiuterus, right salpingectomy and closure.

\section{Discussion:-}

The septate uterus (class V, American Society for Reproductive Medicine Classification ASRM) results from a lack of septum resorption after successful Mullerian fusion and is the most commonly diagnosed Mullerian duct anomaly, occurring in about 55\% of anomalies. But Robert's uterus is a rare type of Mullerian duct anomalies and a variant of septate uterus [1]. While minor congenital uterine abnormalities escape attention, it is the moderate or severe forms which produce gynaecologic or obstetric problems [2]. It was first described by Robert in 1970 [3] and with only a few cases reported so far. Robert's uterus is characterized by uterine septum dividing the endometrial cavity asymmetrically with non communicating hemi uterus due to obstruction by the septum, with one blind horn causing haematometra and one communicating hemiuterus with a single cervix and a normal extrauterine morphology. As a result there is obstruction to menstrual flow in one cavity, resulting in haematometra the cause of cyclical post-menarcheal dysmenorrhea, haematosalpinx and sometimes endometriosis. Patients present with recurrent abdominal pain and severe dysmenorrhoea. They can also present with acute pain of the abdomen as an emergency like Our patient.

Robert's uterus is difficult to diagnose preoperatively and is often misdiagnosed. Investigations done include MRI pelvis, ultrasonography, Hysterosalphingography and hysteroscopy with laparoscopy. Ultrasound sensitivity for diagnosis of Robert's uterus is not high and frequently misdiagnosed as unicornuate uterus with noncommunicating rudimentary horn. But Three-dimensional ultrasound is as good as MRI in providing a correct diagnosis. In the differential diagnosis, unicornuate uterus with noncommunicating rudimentary horn should be considered.

MRI provides excellent tissue characterization helping in reliably differentiating septate from bicornuate uterus and also in diagnosing asymmetric septate uterus [4-6]. ,but is unfortunately expensive. Although both methods require an experienced operator and interpretation by an experienced practitioner. Unfortunately, septate uteri cannot be fully differentiated with Hysterosalphingography given the absence of external fundal imaging. The urinary system, also need to be evaluated for anomalies by USG/CT scan, as they area known association.

Surgery can be done by open or minimally invasive method, Robert's uterus were managed via laparotomy and total horn resection or endometrectomy (Irreversible surgeries) of blinded cavity, abdominal metroplasty, or by combining hysteroscopy/laparoscopy to improve uterine cavity shape and volume taking care to maintain integrity of functional communicating hemiuterus and cervix.[7, 8] 


\section{Conclusion:-}

Robert's uterus is also known as asymmetric septate uterus and is a rare congenital müllerian duct anomaly. Threedimensional ultrasound and MRI are the best modality to demonstrate the uterine septum, normal external fundal contour, haematometra and haematosalpinx. Early and accurate diagnosis of this condition is important in guiding towards appropriate surgical intervention

\section{References:-}

1. 1.Ludwin A, Ludwin I (2015) Comparison of the ESHREESGE and ASRM classifications of Mullerian duct anomalies in everyday practice. Hum Reprod 30: 569580.

2. Dutta D.C. Infertility in Textbook of Gynaecology Including Contraception. 5th Edition. New Central Book Agency, Kolkata, India. Revised reprint 2009; 43 - 45.

3. 3.Robert H (1970) Asymmetrical bifidities with unilateral menstrual retention. Chirurgie 96: 796-799.

4. Behr SC, Courtier JL, Qayyum A. Imaging of müllerian duct anomalies. Radiographics 2012;32:E233-50.

5. Marcal L, Nothaft MA, Coelho F, Volpato R, Iyer R. Mullerian duct anomalies: MR imaging. Abdom Imaging. 2011;36(6):756-64.

6. Bermejo C, Ten MP, Cantarero R, Diaz D, Pérez Pedregosa J, Barrón E. Three-dimensional ultrasound in the diagnosis of Mullerian duct anomalies and concordance with magnetic resonance imaging. Ultrasound Obstet Gynecol. 2010;35(5):593-601.

7. Takeuchi H, Sato Y, Shimanuki H, Kikuchi I, Kumakiri J, Kitade M, Kinoshita K, Accurate preoperative diagnosis and laparoscopic removal of the cavitated non-communicated uterine horn for obstructive Mullerian anomalies. J Obstet Gynaecol Res 2006;32(1):74-9.

8. Perino A, Chianchiano N, Simonaro C, Cittadini E, Endoscopic management of a case of complete septate uterus with unilateral hematometra, Human Reprod 1995;10(8):2171-3. 